МРНТИ 14.35.07

УДК 378.14

https://doi.org/10.51889/2020-2.1728-7901.41

\title{
C.T. Накешева
}

Актюбинский региональный государственный университет им. К. Жубанова, г. Актобе, Казахстан

\section{ИСПОЛЬЗОВАНИЕ ОБРАЗОВАТЕЛЬНЫХ САЙТОВ И МОБИЛЬНЫХ ПРИЛОЖЕНИЙ В ПРОЦЕССЕ ОБУЧЕНИЯ ИНОСТРАННОМУ ЯЗЫКУ НА НЕЯЗЫКОВЫХ ФАКУЛЬТЕТАХ ВУЗА}

Аннотация
В статье рассматриваются возможности использования образовательных ресурсов сети Интернет, социальных сетей в качестве помощников для студентов в процессе изучения иностранного языка в вузе. Нынешнее поколение студентов является активным пользователем различных гаджетов, социальных сетей, цифровых технологий. Однако использование инструментов для досуга значительно отличается от использования их для обучения. Правильный выбор средств обучения способствует достижению целей обучения иностранному языку, оптимизирует и влияет на качество процесса обучения. Автор приводит примеры использования интернет-ресурсов в учебном процессе на традиционных занятиях и занятиях в онлайн режиме.

Сделан обзор наиболее часто используемых сайтов и мобильных приложений с широким выбором упражнений, аутентичного материала, способствующих формированию и совершенствованию лексических и грамматических навыков.

Ключевые слова: учебный процесс, иностранный язык, мобильные приложения, социальные сети, образовательные сайты, интернет-ресурсы, онлайн обучение.

\author{
Андатпа \\ С.T. Накешева \\ Қ. Жұбанов атындавы Ақтөбе өңірлік мемлекеттік университеті, Ақ̧төбе қ., Қазақсттан \\ ЖОО-НЫН ТІЛДІК ЕМЕС ФАКУЛЬТЕТТЕРІНДЕ БІЛІМ БЕРУ САЙТТАРЫ МЕН МОБИЛЬДІ \\ ҚОСЫМШАЛАРДЫ ШЕТ ТІЛІН ОҚЫТУ ҮДЕРІСІНДЕ ПАЙДАЛАНУ
}

Мақалада Интернет желісінің білім беру ресурстарын, әлеуметтік желілерді ЖОО-да шетел тілін оқыту барысында қолдануы студенттерге көмек ретінде пайдалану мүмкіндіктері қарастырылады. Қазіргі студенттер түрлі гаджеттердің, әлеуметтік желілердің, сандық технологиялардың белсенді пайдаланушысы болып табылады. Алайда, құралдарды бос уақыт үшін пайдалануы оларды оқыту үшін пайдалануынан айтарлықтай ерекшеленеді. Оқыту құралдарын дұрыс таңдау шет тілін оқыту мақсаттарына қол жеткізуіне, оқу үрдісінің сапасына ықпал етеді және оңтайландырады. Автор интернет-ресурстарды оқу үрдісінде дәстүрлі сабақтар мен онлайн режимде пайдалану мысалдарын келтіреді. Лексикалық және грамматикалық дағдыларды қалыптастыруға және жетілдіруге ықпал ететін ең жиі қолданылатын сайттар мен мобильді қосымшаларға шолу жасалған.

Түйін сөздер: оқу үдерісі, шет тілі, мобильді қосымшалар, әлеуметтік желілер, білім беру сайттары, интернет-ресурстар, онлайн оқыту.

\section{Abstract}

\section{USING EDUCATIONAL WEBSITES AND MOBILE APPS IN A FOREIGN LANGUAGE TEACHING PROCESS AT NON-LANGUAGE FACULTIES OF THE UNIVERSITY}

Nakesheva S.T.

Aktobe Regional State University named after K. Zhubanov, Aktobe, Kazakhstan

The article discusses the possibilities of using educational resources of the Internet and social networks as assistants for students in the study of a foreign language at university. The current generation of students is an active user of various gadgets, social networks, digital technologies. However, the use of tools for leisure-time differs significantly from their use for training. The right choice of means of instruction contributes to the achievement of foreign language learning objectives, optimizes and influences the quality of the learning process. The author provides examples of the use of Internet resources in the educational process in traditional classes and online activities. An overview of the most frequently used sites and mobile applications with a wide range of exercises, authentic material, contributing to the formation and improvement of lexical and grammatical skills was presented.

Keywords: learning process, foreign language, mobile applications, social networks, educational sites, Internet resources, online learning. 


\section{Введение}

Уровень развития технологий обучения, современные концепции образования, заставляет пересмотреть технологии, применяемые в образовательном процессе, выбирая из них, в первую очередь те, которые повышают эффективность и качество обучения; обеспечивают мотивы к самостоятельной познавательной деятельности. Интерес молодёжи к информационнокоммуникационным технологиям уже давно и прочно закрепил позиции неотьемлемой части как жизни, так и обучения, а потому становится отправной точкой в образовательном процессе.

В настоящее время обучение с применением современных гаджетов уже не является чем-то необычным. Тенденция развития образовательного процесса на данный момент это приоритет индивидуальных цифровых устройств для студентов, цель которых - помощь при обучении.

\section{Методология исследования.}

Целью практической работы автора в вузе за последние годы стало - внедрение цифровых технологий в учебный процесс, формирование компетентности в сфере самостоятельной познавательной деятельности, приобретение навыков самостоятельной работы с большими объёмами информации, полученных из интернета, а также оптимизация процесса обучения иностранному языку.

Внедрение в учебный процесс интернет ресурсов: мобильных приложений, социальных сетей, образовательных сайтов и т.п. поможет эффективного усвоить знания при изучении иностранных языков. Таким образом преподавание английского языка в вузе как одной из дисциплин ООД все больше требует технологически грамотных и эффективных преподавателей, которые смогут составлять подборки обучающих мобильных приложений с упражнениями для улучшения языковых навыков, давать возможность практиковать конкретные навыки (запоминания, грамматические упражнения, идиомы и т.п.), адаптировать инструменты обучения и упражнения к уровню знаний конкретного студента, превращать учебу в развлечение.

Для решения поставленных задач и выбора из многочисленных предложенных интернет-ресурсов наиболее эффективных, автором были использованы следующие методы исследования:

- анализ (работа с литературой, выбор веб-программ, мобильных приложений, образовательных сайтов);

- метод наблюдения (наблюдение за процессом работы со студентами на занятиях);

- метод моделирования (разработка занятий, составление собственных заданий, онлайн-игр, с использованием шаблонов на образовательных интерактивных платформах).

\section{Результаты исследования.}

Так как студенты в АРГУ им.К.Жубанова согласно типовой программе изучают иностранный язык в рамках международных принятых уровней от А1 до С2 в зависимости от уровня подготовки студента на момент поступления, выбор программ и образовательных сайтов варировался. Работа проводилась со студентами первого курса физико-математического факультета вышеупомянутого вуза. На момент исследования в группах с уровнем А1 обучалось 71\% студентов, А2 -18\%, В1-11\%.

В результате исследования, можно сделать выводы, что традиционная форма проведения занятий уже не удовлетворяет потребностей нынешнего поколения студентов, которое увлечено цифровыми информационными технологиями. Как показывает практика, в результате использования мобильных приложений и образовательных сайтов в учебном процессе у студентов повысилась мотивация к изучению языка, процесс обучения проходил динамичнее. Выполнение самостоятельной работы (сдача тестов по индивидуальным ссылкам, ведение страницы в социальных сетях на иностранном языке, съёмка видео для канала YouTube) побудило у многих студентов дух здоровой конкуренции, в результате которого у некоторых студентов замечены положительные изменения в успеваемости.

В группах с уровнем A1 и А2 выполнение практических заданий на чтение и говорение с использованием онлайн-игр, видеоматериала улучшилось произношение и скорость чтения. Хотя, были трудности с восприятием речи на слух. Только просмотр видеоматериала с субтитрами облегчил понимание. Что касается групп с уровнем В1, большинство из них понимало содержание видео без субтитров. Использование онлайн-игр и презентаций в Power Point на сайтаx wordwall.net, en.islcollective.com, allthingsgrammar.com в процессе изучения грамматических тем позволило облегчить их понимание и визуализировать объясняемый материал.

Переход вузов в середине второго семестра учебного года на дистанционную форму обучения в период пандемии COVID-19 работа с интернет-ресурсами стала ещё более интенсивной.

Проанализировав мнения и отзывы студентов об использовании мобильных приложений и образовательных сайтов, а также о занятиях в онлайн-режиме, были сделаны следующие выводы. 
Преимуществами вышеупомянутой формы обучения можно назвать:

- занятия в комфортной домашней обстановке;

- доступ к широкому спектру интернет ресурсов на занятии;

- работа с аутентичными материалами на иностранном языке;

- возможность работать самостоятельно;

- повышение мотивации к изучению иностранного языка;

- расширение кругозора.

Выявлены и следующие недостатки:

- низкая скорость интернет-траффика;

- возникновение технических сбоев;

- недостаток живого общения с преподавателем и однокурсниками.

\section{Дискуссия.}

Согласно теории поколений У. Штрауса и Н. Хоу, основными участниками образовательного процесса на сегодняшний день являются представители поколений «Ү» (родившиеся с 1983-2002 гг.) и «Z» (родившиеся с 2003 г.). Работа преподавателей предполагает необходимый учет определенных особенностей этого поколения. Например, «Z» привыкли «гуглить», формируя поисковый запрос в Интернете, и на четкий запрос получать четкий ответ, так что чтение огромных текстов - не для них. Они привыкли выделять важное из главного и значительно фильтровать количество получаемой информации, что является ключевой компетенцией, необходимой как в информационном обществе, так и обществе, основанном на знаниях $[1,87]$. Опираясь на данную теорию, можно сказать, что студенты физико-математического факультета, с которыми автор работал в ходе исследования, преимущественно являются представителями поколения «Z».

Выбор специальностей связанных с информационными технологиями (автор работал со студентами первого курса специальностей «Информационные технологии», «Вычислительная техника и программное обеспечение», «Компьютерная инженерия») при поступлении в вуз говорит о том, что все они обладают цифровой компетентностью - знаниями, навыками и умениями, необходимых для использования технологий в разных сферах жизнедеятельности. Использование гаджетов для них - это естественный процесс. Они являются одними из самых основных пользователей цифровых инструментов: почти все они обладают ноутбуком с подключением к интернету и смартфоном. Тем не менее, они в основном используют их для воспроизведения музыки, видео и игр или общения с друзьями, редко для работы и учёбы. На данный момент существуют различные системы перевода, приложения для запоминания иностранных слов и фраз и т.д.

Благодаря их доступности, мобильности, простоте использования в ближайшем будущем они станут привычными и естественными средствами обучения. Они не только изменяют место и качество обучения, но и влияют на процесс обучения с дидактической и методической точки зрения [2].

Мультимедиа позволяют сделать учебные материалы по-настоящему наглядными и интересными. Например, запоминать английские буквы гораздо интереснее, обводя их пальцем на планшете или интерактивной доске и подставляя в готовые слова с картинками. В каждом смартфоне в PlayMarket или AppStore существует множество приложений для данных целей. Все мобильные приложения, обучающие программы обновляются по мере появления новых трендов, методик, обратной связи и оценок от пользователей, новой лексики. Преподаватели должны быть на одной волне со студентами. За последние несколько лет учеными были проведены несколько исследований касательно эффективности обучения с помощью образовательных платформ. Было выяснено, что студенты учатся лучше и быстрее, когда преподаватель на занятиях использует возможности мобильных приложений, специальных образовательных программ.

Всё больше и больше высших учебных заведений в мире учат студентов пользоваться социальными сетями, контролировать свою цифровую идентичность и работать вместе, что не является легким навыком для изучения, но очень полезным.

Кроме того, растущее количество информации и дезинформации в интернете сделало культивирование критического мышления жизненно важной миссией [3].

За последние несколько лет многие вузы, в том числе и АРГУ им.К.Жубанова, внедряют дистанционную форму обучения, проводятся онлайн семинары и онлайн занятия. Особенно актуальной и необходимой эта работа стала при переходе вузов Казахстана на дистанционное обучение в период пандемии COVID-19. 
Подробнее остановимся на этапах работы над исследованием. Автору необходимо было определить подходящие методы и приёмы для работы со студентами в соответствии с уровнем владения иностранного языка, подобрать различные программы.

Для эффективной работы со студентами были использованы следующие мобильные приложения: ZOOM, WhatsApp, Instagram, Telegram, Kahoot, Wooclap, Google Earth.

Образовательные сайты:

www.busyteacher.com, www.en.islcollective.com, www.allthingsgrammar.com., www.wordwall.net , www.liveworksheets.com.

Сервис видеохостинга - YouTube, система UNIVER-ARSU.

Для эффективной работы с ссылками на различные сайты и платформы автором были созданы группы в приложении WhatsApp. Онлайн-занятия проходили в формате видеоконференций с помощью приложения ZOOM.

На этапе подготовки к занятиям автор использует методический материал с сайтов www.busyteacher.com, www.en.islcollective.com, www.allthingsgrammar.com., www.wordwall.net , www.liveworksheets.com . Преимущество использования этих ресурсов в том, что материалы актуальны, аутентичны. Здесь вы можете найти готовые разработки по различным темам, составленные учителями английского языка со всего мира. Каждый зарегистрированный участник может скачать материалы бесплатно. Все перечисленные сайты и интернет-платформы зарекомендовали себя как одни из наиболее востребованных.

Для практических занятий с грамматикой и лексикой по темам, изучаемым согласно типовой и рабочей программам дисциплины «Иностранный язык» наиболее часто использовались сайты en.islcollective.com, wordwall.net. Ha caŭme en.islcollective.com можно найти задания для распечатки на принтере, презентации тем в Power Point, видео с заданиями, которые нужно выполнить в процессе просмотра. Wordwall.net. - это сайт с онлайн-играми не только для изучающих иностранный язык, но и игры по другим предметам. Также преподаватель может составить свои игры, используя шаблоны на данном сайте.

Очень популярно нынче приложение INSTAGRAM, которое сейчас можно увидеть в смартфоне каждого студента. В данном приложении очень много обучающих контентов. Например, студентам нравятся страницы учителя английского языка Марии Батхан (@english.maria.batkhan), которая объясняет учебный материал с юмором; страница @englishwithnab носителя языка, который обучает «живому» английскому, со сленгом, идиомами; страница @tips4ielts, страница которая даёт практические советы для успешной сдачи экзамена на сертификат IELTS.

Для того чтобы развивать навыки аудирования, чтения студентам рекомендуется стать подписчиком их кумиров, знаменитостей, ведущих свою страничку на английском языке и писать комментарии к их постам. Это один из способов использования INSTAGRAM с пользой в процессе изучения иностранного языка.

Ещё одна очень интересная страница в INSTAGRAM @greatbigstory. На этой странице размещаются посты с очень интересными историями о людях со всего мира. Все видео сопровождены титрами на английском языке для более эффективного понимания содержания видео.

Для того, чтобы подытожить каждую тему согласно учебного плана, студентам было предложено самим снимать видео, вести блоги в INSTAGRAM на английском. Только практикуя язык, можно им владеть на желанном уровне. У автора собрался архив видео-работ студентов за несколько лет.

Ещё одно мобильное приложение, которое набирает популярность среди пользователей социальных сетей Telegram. На данный момент это приложение не так широко используется как Instagram, но имеет очень много полезных функций. Здесь можно отлично прокачать свои знания английского языка с помощью различных каналов и ботов.

Для пополнения словарного запаса и практики языка используются следующие каналы:

Think English. Канал будет полезен для пополнения словарного запаса. В нем новые слова представлены с объяснениями их значений и примерами применения. Также есть тематические статьи об использовании предлогов и времен, а также идиомы с картинками и примерами.

Wow English. Этот канал поможет расширить словарный запас и освоить полезные фразы для повседневного общения. На канале новые слова и фразы публикуются подборками с конкретной темой и областью применения: телевидение, время, чувства и эмоции и т.д. Также можно найти полезные выражения для публичного выступления или, например, похода к врачу.

Minute Memes. Не секрет, что информация воспринимается и запоминается лучше, если сопровождается картинками, особенно смешными. На этом канале фразы представляются с помощью 
мемов, гифов и кадров из известных фильмов. Это поможет студентам не только выучить новые слова/фразы, но и познакомиться с разговорным английским.

Movies \& Books in English. Настоящая находка для любителей кино и литературы. Здесь представлены фильмы с описанием и ссылкой на просмотр его полной версии на английском, а книги можно скачать в PDF формате. Также на канале есть возможность отправить запрос для добавления конкретного фильма или книги.

Традиционные формы контроля можно заменить на более интересные виды, используя те же современные гаджеты. Контроль знаний можно провести в очень занимательной форме, благодаря таким приложениям как kahoot или triventy, Jeopardy. Эти приложения можно использовать не только для изучения языков, а вообще для контроля знаний или как викторину. Сначала надо зарегистрироваться на сайте для учителей www.getkahoot.com, составить тест, используя картинки, таймер. А можно использовать уже готовые тесты. Сам вопрос проецируется на экран интерактивной доски или ноутбука, а студенты присоединяются к тесту с помощью своих смартфонов и специального кода для теста. Все участники тестирования входят в игру под своими никами. Отвечая на вопрос они нажимают на фигуры определённого цвета. После окончания заданного времени kahoot выдаёт правильный ответ и показывает, кто ответил быстрее. Приложение triventy аналогичное, но может использоваться без доски и ноутбука. Јеоpardy - это викторина, состоящая из вопросов разной сложности (по принципу игры «Своя игра»). Викторину можно составить с помощью сайта JeopardyLabs или с помощью программы PowerPoint. Относительно недавно появилась ещё одно новое приложение www.wooclap.com, очень полезное не только для преподавателей разных предметов, но и для бизнесменов.

Преимущества данного приложения в следующем:

- в отличие от kahoot вопросы даются с многовариантными ответами. Участники выбирают один или несколько ответов;

- можно выявить, что думают участники по заданному вопросу в течение секунд;

- для опроса можно использовать изображения, на котором нужно определить зону правильного ответа;

- дать задание на ассоциации к словам, результаты данного задания отображаются в режиме реального времени и выводятся на экран наиболее часто повторяющиеся слова;

- отсортировать элементы в определённом порядке;

- участники могут написать пропущенные слова в тексте;

- быстро вставлять дополнительный текст и изображения в презентацию, чтобы помочь участникам лучше воспринять материал;

- участники могут поделиться мнениями по заданной теме и сортировать их мнения по категориям;

- вводить URL-адрес видеоматериала или mp4-файла, чтобы добавить привлекательный контент в презентацию [4].

Wooclap работает с программой Exel, чтобы преобразовать результаты в презентации в формат spreadsheet, скачать сетку результатов и наблюдать индивидуальные и общие показатели.

Тесты преподаватели могут составить сами или выбрать из готовых, исходя из целей, уровня подготовленности, индивидуальных особенностей студентов.

Студенты, принимая участие в подобных интерактивных формах контроля, забывают о своих комплексах, для них это увлекательная игра, совсем не похожая на обычное бланочное тестирование.

Для подготовки к важным экзаменам помогут каналы с соответствующими уровням, который нужны на экзамене. На канале English Gate Learners есть информация по грамматике, новые слова/фразы и идиомы представляются через картинки или в формате видео со своими объяснениями [5]. При изучении тем «Страны мира», «Путешествие», «Города» наши студенты используют приложение «Планета Земля» (Google Earth). Особенность этого приложения в том, что карты в приложении можно посмотреть в 3D формате, а также прогуляться по улицам городов с помощью фото, сделанных панорамной съёмкой. В качестве задания для студентов автором было предложено составить маршрут своего путешествия, обозначая все населённые пункты, улицы и т.д.

Конечно же, очень много материала использовалось с Youtube. Помимо видеоклипов с песнями и видеоматериалов на различные темы, студентам рекомендуются к просмотру каналы популярных видеоблогеров, обучающих английскому языку. Большой популярностью среди молодёжи всего мира пользуется канал Ted-Ed. На этом канале можно найти видеоматериалы на английском языке по различным темам: история, медицина, информатика, литература и т.п. Этот канал может заинтересовать также преподавателей, работающих по CLIL-технологиям. Видеоматериалы 
представлены в виде анимационных фильмов, лекций известных личностей мира, что повышает интерес к просмотру. Также в описании к видео даётся ссылка на экспресс-тесты по содержанию видео, где преподаватели могут проверить уровень усвоения информации. Как показывает практика, студенты узнают много нового материала о своей специальности именно на уроках иностранного языка благодаря актуальным видеоматериалам из Youtube.

Просмотр сериалов на иностранном языке - ещё одно популярное задание среди наших студентов. Желательно держать под рукой блокнот и ручку для записи новых слов. Студентам рекомендуется попробовать записать новые слова из первой серии сезона сериала, просмотрите весь сезон и вернуться к словам из первой серии. Больше половины уже не будут новыми, ведь в сериалах часто речь идет примерно об одном и том же, а значит, через 10-15 серий они уже автоматически смогут понимать многие слова, которые еще недавно были новыми. YouTube используется также в качестве инструмента для оценки творческой работы студентов. Например, после изучения тем «Мой родной город-Актобе», «Наша студенческая жизнь» в качестве задания предлагается снять видеоролики на данные темы и разместить их в YouTube. Нужно отметить, что работа такого типа очень сплачивает студентов, развивает командный дух, ребята с большой ответственностью и вдохновением относятся к съёмкам видеоматериала. В перспективе же нам следует научиться проактивно воспринимать технологии - вычленяя самые эффективные и полезные в обучении инструменты и отсеивая остальные. В этом случае преподавание английского языка перейдет на качественно новый уровень [6].

При правильном использовании, мобильные устройства и инструменты Web 2.0 гарантируют не только удобство и новизну, но и действенное обучение, приносящее реальные, ощутимые практические результаты современному студенту, изучающему иностранный язык. По словам генерального секретаря Европейского фонда гарантий качества в электронном обучении (EFQUEL) Клаудио Донди: «Образование будущего - открытое, с использованием ИКТ, ориентированное на учащегося, более глобализованное, стремящееся к стандартизации. Многое меняется в образовании: мотивация, контент, инклюзивность, качество, преподавание, цели обучения, компетенции, управление, методы оценки знаний» [7]. Разработчики учебных программ должны учитывать новые образовательные технологии, а преподаватели овладевать ими и эффективно применять.

\section{Заключение.}

Анализируя работу студентов со всеми вышеперечисленными ресурсами при изучении иностранного языка, стоить отметить, что эффективность и успех работы с ними зависит также от базового уровня подготовленности студентов.

К подготовке к занятиям в каждой группе нужно подходить дифференцированно, принимая во внимание коммуникативную сферу, отражающую содержание уровня обучения, набор речевых тем, типичные ситуации общения. Необходимо также и преподавателю постоянно повышать квалификацию и развивать свою цифровую компетентность, для того чтобы сделав анализ контента мобильных приложений и образовательных сайтов, грамотно составлять алгоритм работы с ними.

\section{Список использованной литературы}

1 Воскресенский А.А., Рабош В.А., Сунягина А.Г. Постматериальные ценности поколения $Z$ на пути к обществу знаний - к постановке проблемы // Общество. Среда. Развитие (Terra Hитапа) - 2018, №1 (46). C. 84-87

2 Герасименко Т. Л., Грубин И. В., Гулая Т.М., Жидкова О.Н., Романова С.А.. Sтагt-технологии (вебинары и социальные сети) в преподавании иностранного языка в неязыковом вузе // Экономика, статистика и информатика. Вестник УМО. -2012, №5. С.9-12.

3 Students face the challenge of digital technology. [Электрон.pecypc].-2019.-URL: https://www.wooclap.com/en/blog/inside-classrooms/students-face-the-challenge-of-digital-technology/(dama обращения: 13.01.2020)

4 Live Learning. [Электрон.ресурc].-2019.-URL: https://www.wooclap.com/en/features/votes/(дama обращения:13.01.2020)

5 Smart Learning Programme for Specialists of the Republic of Kazakhstan Professional development for teachers based on Smart Learning. Korea Soongsil Cyber University. 2014.

6 Тимофеева Е. Преподаватели vs. Технологические платформы:: кто победит? - [Электрон.ресурс].-2020.URL: https://skyteach.ru/2020/01/13/prepodavateli-vs-texnologicheskie-platformy-kto-pobedit/ (дата обращения:15.01.2020)

7 Тихомирова Н.В. О тенденциях в сфере образования. [Электрон.ресурс].-2016.-URL: http://ntihomirova.livejournal.com/44526.html/ (дата обращения: 15.01.2020) 


\section{References:}

1 Voskresenskij A.A., Rabosh V.A., Sunjagina A.G. (2018) Postmaterial'nye cennosti pokolenija Z na puti $k$ obshhestvu znanij - k postanovke problemy Obshhestvo. Sreda. Razvitie (Terra Humana), №1(46). S. 84-87.

2 Gerasimenko T. L., Grubin I. V., Gulaja T.M., Zhidkova O.N., Romanova S.A.. (2012) Smart-tehnologii (vebinary $i$ social'nye seti) $v$ prepodavanii inostrannogo jazyka $v$ nejazykovom vuze Jekonomika, statistika $i$ informatika. Vestnik UMO. №5. 9-12

3 Students face the challenge of digital technology. [Jelektron.resurs]. (2019) URL: https://www.wooclap.com/en/blog/inside-classrooms/students-face-the-challenge-of-digital-technology/(data obrashhenija: 13.01.2020)

4 Live Learning. [Jelektron.resurs]. (2019) URL: https://www.wooclap.com/en/features/votes/(data obrashhenija:13.01.2020)

5 Smart Learning Programme for Specialists of the Republic of Kazakhstan Professional development for teachers based on Smart Learning. (2014) Korea Soongsil Cyber University.

6 Timofeeva E. Prepodavateli vs. Tehnologicheskie platformy: kto pobedit? [Jelektron.resurs]. (2020) URL: https://skyteach.ru/2020/01/13/prepodavateli-vs-texnologicheskie-platformy-kto-pobedit/ (data obrashhenija:15.01.2020)

7 Tihomirova N.V. O tendencijah $v$ sfere obrazovanija. [Jelektron.resurs]. (2016) URL: http://ntihomirova.livejournal.com/44526.html/(data obrashhenija: 15.01.2020) 